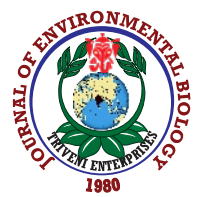

\title{
Effect of phosphorous in combination with biofertilizers on growth, yield and quality of strawberry cv. Winter Dawn
}

\author{
G.Chandramohan Reddy*, R.K. Goyal and A.K. Godara \\ Department of Horticulture, College of Agriculture, CCS Haryana Agricultural University, Hisar-125004, India \\ *Corresponding Author Email : reddyhorti96@gmail.com
}

\begin{abstract}
Aim: This study was carried out to investigate the effect of biofertilizers in combination with phosphorus rates on growth, yield and quality of strawberry.

Methodology: The experiment was conducted during the year 2017-18 and 2018-19 at hi-tech greenhouse of the Department of Horticulture, CCS Haryana Agricultural University, Hisar. The experiment was arranged in a factorial completely randomized design with four phosphorus fertilizer rates $(0,80,100$ and $120 \%$ RDP per plant) and three biofertilizers (control, VAM and PSB) at five replicates. Growth and yield parameter were estimated. Quality traits, viz., TSS, acidity, ascorbic acid, anthocyanin and juice content of fruits were also measured at maturity stages.

Results: All the possible combinations of phosphorous and biofertilizers were found to have significant influence on the vegetative growth, yield and quality parameters of strawberry. The minimum number of days taken to first flowering, maximum fruit weight, size and fruit yield per plant were recorded with $100 \%$ RDP along with VAM. TSS and ascorbic acid were noted maximum with combined application of $120 \%$ RDP and biofertilizers.
\end{abstract}

Interpretation: VAM and PSB inoculation in combination with 100 percent recommended dose of phosphorous showed maximum vegetative growth, yield and quality of strawberry as compared to non-biofertilizer inoculation.

Key words: Biofertilizers, Phosphorous, Strawberry, Vesicular arbuscular mycorrhiza

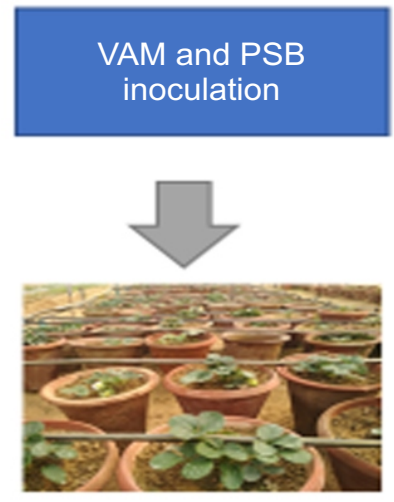

Quality berry production

How to cite : Reddy, G.Chandramohan, R.K. Goyal and A.K. Godara: Effect of phosphorous in combination with biofertilizers on the growth, yield and quality of strawberry cv. Winter Dawn. J. Environ. Biol., 42, 727-734 (2021). 


\section{Introduction}

The cultivated strawberry (Fragaria $x$ ananassa Duch.) is a hybrid between Fragaria virginiana Duch. and Fragaria chilonensis (L.) Duch. (Hokanson and Maas, 2001) that belongs to family Rosaceae, spreads from Arctic to the Tropics with USA (34.0\%) followed by Turkey (8.20\%), Spain $(5.60 \%)$, Egypt (5.40\%) and Mexico (5.30\%) as the leading producers (FAOSTAT, 2018). Strawberry yields quickest returns in shortest time. Daily consumption of strawberry can check certain types of cancer, obesity, cardiovascular diseases, diabetes and cellular injury induced by reactive oxygen species (Wang and Lewers, 2007; Tulipani et al., 2009; He and Giusti 2010; Giampieri et al., 2012). Modern day intensive crop cultivation for increasing production requires huge application of costly chemical fertilizers. Abundant and indiscriminate prolonged usage of inorganic chemical fertilizers and pesticides increases the cost of production, causes soil, water and environment pollution through de nitrification, runoff, leaching and volatilization, adversely affecting soil fauna, flora and soil fertility (Hedley et al., 1982; Seneviratne, 2009). Hence, to tackle these problems for sustainable production of crops, biofertilizers and organic manures are the best alternatives.

Beneficial micro-organisms like Pseudomonas, Bacillus, Mycorrhizae fungi, Aspergillus and Penicillium present in biofertilizers influence plant growth and health by enhancing nutrient availability, uptake and biological activity in the rhizosphere, P-solubilization and mobilization of P, Zn, Fe, Mo to varying level and by producing phytohormones (auxins, cytokinins, gibberellins), antibiotics and secondary metabolites that help host plants to resist diseases and insect pests and withstand abiotic stress conditions. Likewise, organic farm yard and vermicompost manures improve soil physical conditions and supply all essential macro elements and microelements (Tawaraya et al., 2006; Pandit et al., 2013; Reddy and Goyal et al., 2020) to fulfil plant requirements. The organic and biological resources are renewable sources, ecofriendly and available at low cost, which are of much importance in the sustainable crop production.

Biofertilizers are now used in numerous agricultural and horticultural systems for reducing the cost of crop production and minimizing environmental pollution (Han and Lee, 2005; Glick et al., 2007; Sindhu et al., 2010). Soil fertility is most vital factor affecting the productivity of strawberry. Strawberry plants have shallow root system and need effective and balanced nutrient management throughout cropping period. The application of biofertilizer along with organic or inorganic fertilizers boost the growth and quality production of plants (Sinha et al., 2009). This combined application improves soil health (Patil, 2010) by increasing fertilizer use efficiency and nutrient uptake, growth and yield (Karlidag et al., 2009; Khalil, 2012; Hassan, 2015; Reddy and Goyal et al., 2020). View of the above, the effects of different phosphorus rates and biofertilizers on strawberry production and quality under greenhouse conditions. Was investigated.

\section{Materials and Methods}

Experimental site, geographical location and climate: This study was conducted in Hitech greenhouse during the year 201718 and 2018-19 at Department of Horticulture, CCS Haryana Agricultural University, Hisar (Haryana). Hisar is located in semiarid climatic zone of Haryana with hot and dry summer and extremely cold winter, intervened by short West monsoon during July - August. The mean average rainfall is about $420 \mathrm{~mm}$ over a period of year. Biochemical analysis of fruits was carried out at Post-harvest laboratory, Department of Horticulture and nutrient analysis was carried out at Department of Soil Science, College of Agriculture, CCS HAU, Hisar. A representative soil sample was collected from sand dunes and collected samples were mixed properly, dried and subjected to physical and chemical analysis.

The soil was red loamy in texture with $\mathrm{pH} 7.20,0.40 \mathrm{dS}$ $\mathrm{m}^{-1}$, EC $0.23 \%$, Organic carbon available $\mathrm{N} 91.0 \mathrm{~kg} \mathrm{ha}^{-1}, 21.0 \mathrm{~kg}$ ha $^{-1}$ available $\mathrm{P}$ and $225.00 \mathrm{~kg} \mathrm{ha}^{-1}$ available $\mathrm{K}$. here representative soil sample means, we have taken 10 soil samples in a particular area (10 times) for pre analyzing of soil characters and it is collectively called as representative sample). The greenhouse was constructed with steel pipes covered with 200 micron ultraviolet stabilized polyethylene sheet and movable shade nets were also fitted in the greenhouse providing requisite sunlight or shade for crops based on requirements. It was also fitted with fan-pad cooling system, installed foggers and micro-irrigation system (drip and micro-jet) for automated fertigation and climate (temperature, relative humidity) control during the experimental period. Each twelve inches earthen pots were filled sand and vermicompost (3: 1 ratio). The vermicompost used for pot filing had (2.29\%) available N, (1.07\%) available P and (1.59\%) available K.

Experimental setup: The treatments involved four $P$ fertilizer rates of $0,80,100$ and $120 \%$ recommended dose of phosphorous (RDP) plant ${ }^{-1}$ and two biofertilizers (VAM and PSB) inoculation, in a complete randomized design with five replications. Uniform runners were selected for planting and single healthy uniform runners were planted in each pot after treating with copper oxychloride for $10 \mathrm{~min}$. The planting was done in $2^{\text {nd }}$ week of October in both consecutive years (2017-18 and 2018-19). Gap filling was done 7-10 days after transplanting to ensure optimum plant population in the research plots. The recommended doses of fertilizers (NPK 1.95:0.8:2.75 $\mathrm{g} \mathrm{plant}^{-1}$ ) was applied based on treatment imposition in the form of water-soluble fertilizers (Urea, 19:19:19 and Sulphate of potash) through drip-fertigation. The fertigation schedule was followed at weekly interval, a week after transplanting. The biofertilizers used in the experiment were procured from the Department of Microbiology, CCS Haryana Agricultural University, Hisar whereas vascular arbuscular mycorrhiza (VAM) was procured from the Department of Microbiology, Indian Agricultural Research Institute, New Delhi. Phosphorus solubilizing bacteria (PSB) was applied to the 
rhizosphere of the plant after 20 and 40 days of planting and $5 \mathrm{~mm}$ broth of each strain was applied near root periphery of plant. Pest and disease control were performed according to local management practices.

Sampling and measurement: Growth parameters such as plant height and spread was measured with a scale and the average of both was expressed as plant height and spread. The number of leaves per plant was counted at 120 DAT and the average number of leaves per plant was expressed in number, crown diameter of plant was measured with a vernier scale $( \pm 0.05 \mathrm{~mm}$ accuracy). The number of days taken from planting to the appearance of first flower in each replication was counted and the mean days required to first flower was worked out and expressed in days. Yield parameter such as fresh weight of fruits in each replication were randomly selected to determine the average fruit weight using electronic balance and the data were expressed in g per fruit. Fruit size (length and breadth) was also determined in the samples by 'Inox' Vernier scale $( \pm 0.05 \mathrm{~mm}$ accuracy) and expressed in millimetre.

The fruits were harvested from different pickings and average was worked out, which was expressed as number of fruits per plant. The yield of fruits per plant was noted down from each treatment and in each picking. The total weight of fruits harvested in each picking was computed and expressed in yield per plant in grams. Quality traits, viz., Total soluble solids, acidity, ascorbic acid, anthocyanin content and juice content of fruit were measured at commercial maturity stages. Total soluble solids, acidity and ascorbic acid were estimated using standard procedures (AOAC, 1990) and anthocyanin content was determined using $\mathrm{pH}$ differential spectrophotometer method suggested by Cheng and Breen (1991); Tonutare et al. (2014).

Statistical analyses: The data of plant growth, fruit yield and quality parameters were analysed statistically and results interpreted as method described by Panse and Sukhatme (1954). In order to evaluate the comparative performance of various treatments, the data were analysed by using the technique of analysis of variance described by Fisher (2006). All the tests of significance were made at $5 \%$ level of significance. The data were analyzed with the help of a windowbased computer package OPSTAT.

\section{Results and Discussion}

The results showed that the levels of phosphorous application made a significant improvement in all growth characters (Table 1). The maximum plant height (18.65 and 20.03 $\mathrm{cm}$ ) was observed with 120 per cent recommended dose of phosphorous per plant, which was statically at par with 100 per cent recommended dose of phosphorous (18.53 and $19.87 \mathrm{~cm}$ ), however, maximum plant spread $(29.90$ and $31.12 \mathrm{~cm})$, number of leaves per plant (19.90 and 21.03), maximum crown diameter (10.98 and $11.72 \mathrm{~mm}$ ) and the minimum number of days taken to first flower initiation (36.83 and 37.72 days) was observed with
$100 \%$ RDP, thereafter, it decreased with increased phosphorus rates $(120 \% \mathrm{RDP})$ during both the years of study. These results may be due to continuous application of water-soluble phosphatic fertilizer along with recommended dose of nitrogen and potassium, which enhanced nutrient uptake, thus, eventually increased plant height and spread (Ahmed et al., 2018; Singh et al., 2019) in strawberry. Odongo et al. (2008) and Ahmed et al. (2018) also reported that balanced application of phosphorous promoted growth in strawberry.

To further explore the potential application of VAM and PSB also significantly enhanced the vegetative attributes during both the years of study. Plants inoculated with VAM recorded maximum plant height ( 17.76 and $18.86 \mathrm{~cm}$ ), plant spread (28.68 and $29.64 \mathrm{~cm}$ ), number of leaves per plant (18.95 and 19.73), crown diameter ( 10.78 and $11.31 \mathrm{~mm}$ ) and minimum days taken to first flower initiation ( 37.45 and 38.26 days), however, it was at par with PSB inoculation and the minimum was found in control treatment during both the years of investigation (Table 1). Biofertilizers such as VAM and PSB boost secretion of organic acids and enzymes act as mineralization of immobile form of phosphates and growth promoting substances, which promotes plants growth (Wani et al., 2013; Bona et al., 2015). The interaction between phosphorous and biofertilizers was found significant during both the years. The results are in conformation with the findings of Nazir et al. (2006) and singh et al. (2019) in strawberry, which might be due to VAM and PSB enhances the availability of all nutrients, which forces the early flower production in strawberry.

Data presented in Table 2 shows that the maximum number of fruits (20.69 and 21.35) per plant, fresh weight of fruit (13.69 and $14.59 \mathrm{~g}$ ), fruit length (33.82 and $35.50 \mathrm{~mm}$ ), fruit width (26.41 and $27.64 \mathrm{~mm}$ ) and fruit yield per plant (284.55 and 312.05 g) was recorded with $100 \%$ RDP, furthermore, enhancement of phosphorus rates (120\% RDP) did not show any significant impact on these parameters. These observations are in conformity with those of Sonsteby et al. (2004) and Latef and Chaoxing (2011) who observed maximum number of fruits with higher fruit weight due to application of $100 \%$ RDF through water soluble fertilizers in strawberry. The maximum yield might be due to balanced nutrition at all stages of growth, which increased duration of flowering and fruit set (Kirimi et al., 2011; Zhao et al., 2005; Karma et al., 2017).

Application of biofertilizers significantly enhanced the yield parameters. Plants inoculated with VAM produced the maximum number of fruits per plant (20.01 and $20.79 \mathrm{~g})$, fresh weight (13.17 and $14.05 \mathrm{~g})$, fruit length ( 32.93 and $34.49 \mathrm{~mm}$ ), fruit width $(25.04$ and $26.24 \mathrm{~mm}$ ) and fruit yield $(268.22$ and $296.41 \mathrm{~g}$ ), which was statistically at par with PSB inoculation in all the above parameters whereas the minimum yield were obtained from the plants of control treatment during the year 2017-18 and 2018-19, respectively. The interaction effect of phosphorous levels and biofertilizers were found significant for fruit yield per plant during both the years of investigation and the 
Table 1: Growth parameters of strawberry cultivar Winter Dawn under different phosphorous rates in combination with VAM and PSB

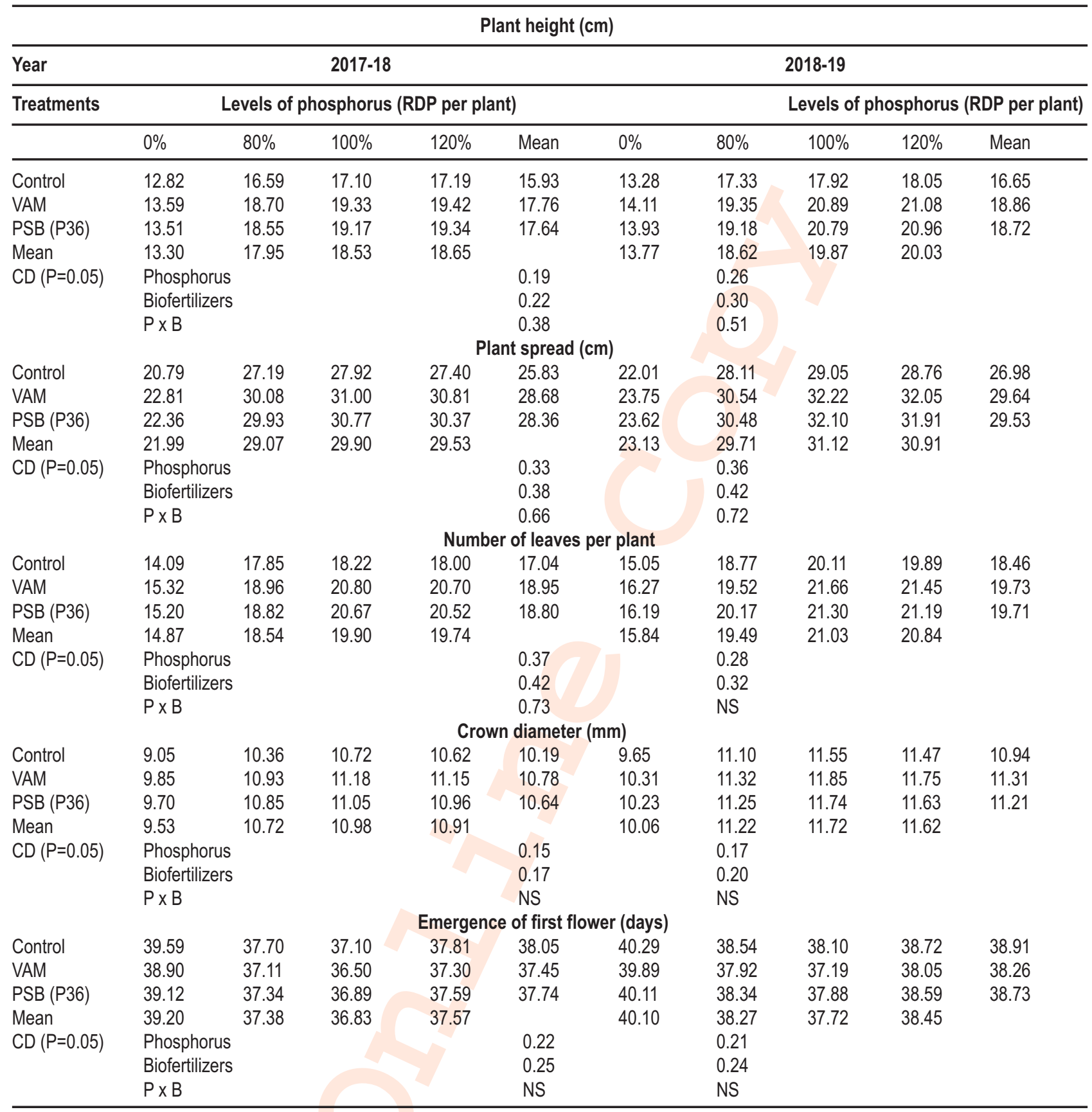

maximum fruit yield per plant (309.23 and $341.93 \mathrm{~g})$ was recorded with the inoculation of VAM along with $100 \%$ RDP, which was statistically at par with VAM $+120 \%$ RDP (307.80 and $340.20 \mathrm{~g}), \mathrm{PSB}+100 \% \operatorname{RDP}(301.41$ and $335.17 \mathrm{~g})$ and PSB + $120 \% \operatorname{RDP}(297.94$ and $333.54 \mathrm{~g})$, and the minimum fruit yield (142.84 and $155.14 \mathrm{~g})$ per plant was recorded in control in year 2017-18 and 2018-19, respectively. The results of present study are in line with the findings of Esmatullah et al. (2017) who noted that VAM inoculation significantly increased the fruit number, fruit weight and fruit yield of strawberry, which might be due to potential role of VAM in solubilization of insoluble phosphorus, uptake and proliferation of beneficial organisms in the rhizosphere. VAM inoculation are known to affect hormone production (auxin, gibberellins, and cytokinin) (Gunesh et al., 2009), photosynthate availability (Kirad et al., 2009; Verma and Rao, 2013) and better soil moisture retention, which promotes early flowering, prolonged flowering period, increased number of flowers, fruits, as observed in the present study. Similar 
Table 2: Yield parameters of strawberry cultivar Winter Dawn under different phosphorous rates in combination with VAM and PSB

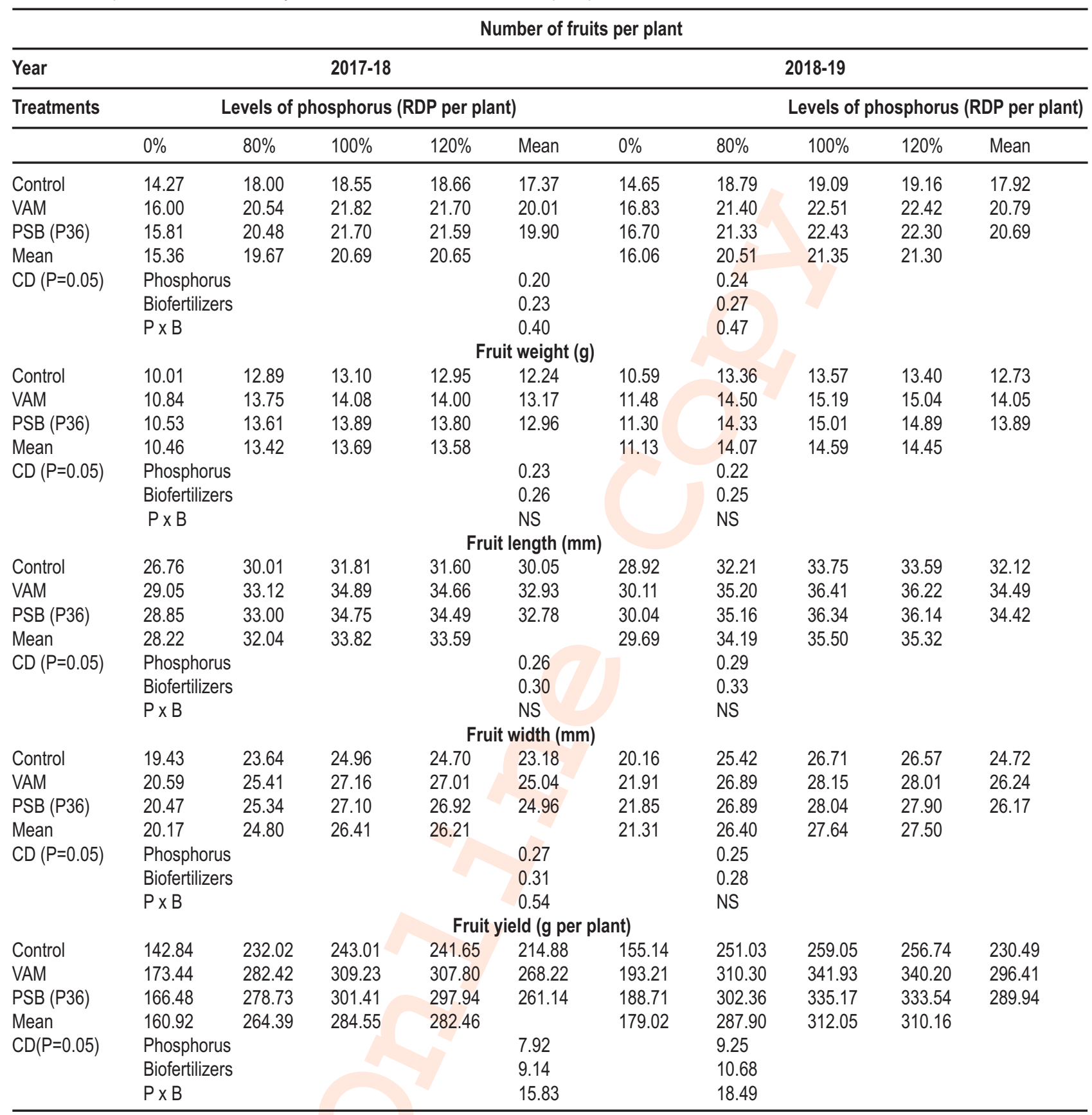

observations were also made by Hazarika et al., 2015; Subraya et al., 2017) in strawberry. On the other hand, the increased application of phosphorous significantly affected all quality parameters. The data presented in Table 3 reveals that the maximum juice (62.33 and 63.04\%), anthocyanin (41.51 and

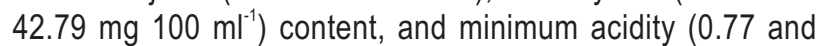
$0.76 \%$ ) was found in $100 \%$ RDP, however, maximum TSS (7.46

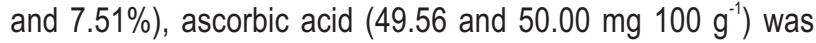
found in fruits of strawberry plants fertilized with $120 \%$ RDP, which was statistically at par with $100 \%$ RDP during the year 2017-18 and 2018-19, respectively.

These results are in conformity with Estrada-Ortiz et al. (2013) who recorded maximum TSS and ascorbic acid content when plants were supplied with higher dose of phosphorous, Which might be due to the continuous availability of phosphorous and greater availability of sugars and substrates for vitamin $\mathrm{C}$ biosynthesis. It is inferred from the data that among the 
Table 3: Quality parameters of strawberry cultivar Winter Dawn under different phosphorous rates in combination with VAM and PSB

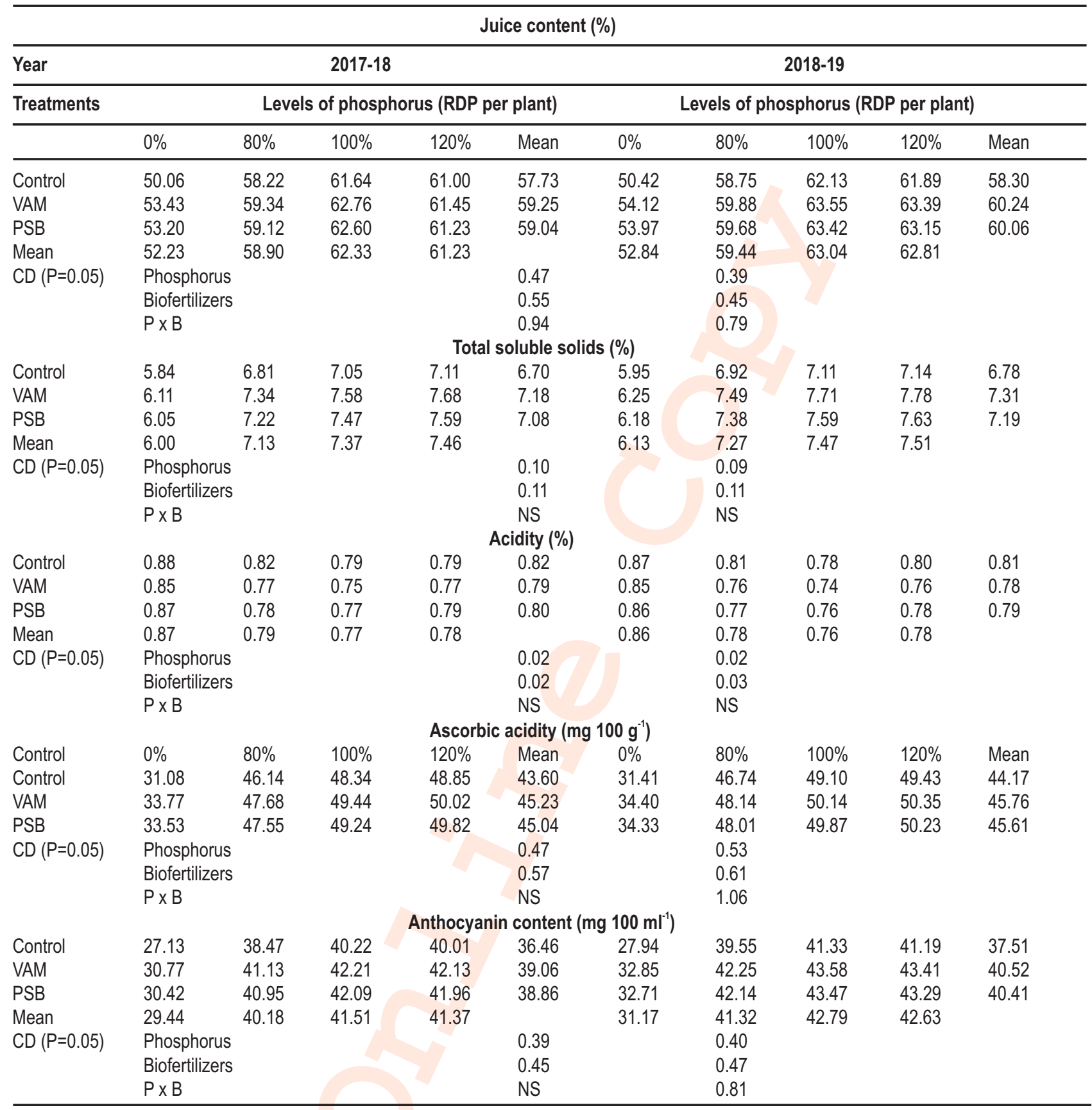

biofertilizers, maximum juice content (59.25 and 60.24\%), TSS (7.18 and 7.31\%), anthocyanin content (39.06 and $40.52 \mathrm{mg} 100$

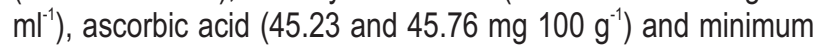
acidity $(0.79$ and $0.78 \%)$ was observed in fruits harvested from the plants inoculated with VAM, which was statistically at par with PSB inoculation, and the minimum was recorded in control treatment in both years, respectively. The results of current study are in line with the findings of Lingua et al., 2013; Cruz-Rus et al., 2011 , who reported that increase in fruit quality might be due to solubilization of phosphate and greater availability of sugars (fructose and glucose) and substrates for vitamin $\mathrm{C}$ biosynthesis. Inoculation of VAM resulted in higher concentration of anthocyanins in strawberry fruits due to symbiosis induced increase in cyanidin 3-glucoside and other phenolics (Castellanos-Morales et al., 2010; Hazarika et al., 2015; Singh et al., 2018). The results demonstrated a large reduction in growth, yield and quality when less $P$ rates with and without biofertilizers inoculation, however, biofertilizer inoculated plants showed good 
performance than non-inoculated plants. It is concluded that 100 percent recommended dose of phosphorous in combination of VAM and PSB inoculation treatments showed better results with respect to growth, yield and quality parameters in strawberry, furthermore, higher $\mathrm{P}$ rates 120\% RDP not impact on growth, yield of strawberry. Overall, applying 100 percent recommended dose of phosphorous in combination with biofertilizers produced the higher vegetative growth, yield and quality of strawberry cv. Winter Dawn as compared to other combinations.

\section{Acknowledgment}

The authors are thankful to Precision Farming Development Centre, CCS HAU, Hisar for providing necessary field and laboratory facilities during the course of investigation.

\section{Add-on Information}

Author' contribution: G.Chandramohan Reddy: Data collection, Field maintain; R.K. Goyal: Technical guidance evaluation; A.K. Godara: Manuscript preparation.

Research content: The research content is original and has not been published elsewhere

\section{Ethical approval: NotApplicable}

Conflict of interest: The authors declare that there is no conflict of interest.

\section{Data from other sources: NotApplicable}

Consent to publish: All authors agree to publish the paper in Journal of Environmental Biology.

\section{References}

Ahmed, R., M.R. Karim, M.A. Quddus, S. Ahmed and M.A. Siddiky: Response of strawberry to NPKS on yield in terrace soil. Bangladesh J.Agri. Res., 43, 89-97 (2018).

AOAC: Official Methods of Analysis. $15^{\text {th }} \mathrm{Edn}$.: AOAC, Washington DC, USA(1990).

Bona, E., G. Lingua, P. Manassero, S. Cantamessa, F. Marsano, V. Todeschini and E. Gamalero: AM fungi and PGP pseudomonads increase flowering, fruit production, and vitamin content in strawberry grown at low nitrogen and phosphorus levels. Mycorrhiza., 25, 181-193 (2015).

Castellanos-Morales, V., J. Villegas, S. Wendelin, H. Vierheilig, R. Eder and R. Cardenas-Navarro: Root colonization by the arbuscular mycorrhizal fungus Glomus intraradices alters the quality of strawberry fruits (Fragaria $x$ ananassa Duch.) at different nitrogen levels. J. Sci. Food Agric., 90, 1774-1782 (2010).

Chandramohan, R.G. and R.K. Goyal: Growth, yield and quality of strawberry as affected by fertilizer $\mathrm{N}$ rate and biofertilizers inoculation under greenhouse conditions. J. Plant Nutri., 10, 180$192(2020)$

Cheng, G.W. and P.J. Breen: Activity of phenylalanine ammonia-lyase and concentrations of anthocyanins and phenolics in developing strawberry fruit. J. American Soc. Hort. Sci., 116, 865-869 (1991).

Esmatullah, A., M.K. Honnabyraiah, S. Ashok, J. A. Dinakara and V. Rao: Impact of integrated nutrient management on yield and quality parameters of strawberry (Fragaria x ananassa Duch.) cv. Sabrina under polyhouse. Int. J. Curr. Micro. Appl. Sci., 6, 3481-3487 (2017).

Estrada-Ortiz, E., L.I. Trejo-Tellez, F.C. Gomez-Merino, R. NunezEscobar and M. Sandoval-Villa: The effects of phosphite on strawberry yield and fruit quality. J. Soil Sci. Plant Nutri., 13, 612$620(2013)$

FAOSTAT: Food and Agriculture Organization of the United Nation, Rome, Italy (2018). http://faostat.fao.org

Fisher, R.A.: Statistical Methods for Research Workers. Genesis Publishing Pvt. Ltd. Edenburg, London, p. 224. (2006).

Giampieri, F., S. Tulipani, J.M. Alvarez-Suarez, J.L. Quiles, B. Mezzetti and M. Battino: The strawberry: Composition, nutritional quality and impact on human health. Nutrition, 28, 9-19 (2012).

Glick, B.R., B. Todorovic, J. Czarny, Z. Cheng, J. Duan and B. McConkey: Promotion of plant growth by bacterial ACC deaminase. Critical Rev. Plant Sci., 26, 227-242 (2007).

Guneşh, A., N. Ataoglu, M. Turan, A. Eşitken and Q.M. Ketterings: Effects of phosphate - solubilizing microorganisms on strawberry yield and nutrient concentrations. J. PI. Nut. Soil Sci., 3, 385-392 (2009).

Han, H.S. and K.D. Lee: Phosphate and potassium solubilizing bacteria effect on mineral uptake, availability and growth of egg plant. Res. J. Agric. Bio. Sci., 1, 176-180 (2005).

Hassan, A.H.: Effect of nitrogen fertilizer in the form of organic, inorganic and biofertilizer applications on growth, yield and quality of strawberry. Middle East J. Appl. Sci., 5, 604-617 (2015).

Hazarika, T.K., Z. Ralte, B.P. Nautiyal and A.C. Shukla: Influence of biofertilizers and bio-regulators on growth, yield and quality of strawberry (Fragaria $\times$ ananassa). Indian J. Agri. Sci., 9,12011205(2015)

He, J. and M.M. Giusti: Anthocyanins: Natural colorants with healthpromoting properties. Annual. Rev. Food Sci. Tech., 1, 163-187 (2010).

Hedley, M.J., R.E. White and P.H. Nye: Plant induced changes in the rhizosphere of rape (Brassica napus var. Emerald) seedlings: Changes in $L$ value, soil phosphate fractions and phosphatase activity. New Phytologist., 91, 45-56 (1982).

Hokanson, S.C. and J.L. Maas: Strawberry biotechnology. Plant Breeding Rev., 21, 139-179 (2001).

Karlidag, H., E. Yildirim, M. Turan and M.F. Donmez: Effect of plant growth-promoting bacteria on mineral organic fertilizer use efficiency, plant growth and mineral contents of strawberry (Fragaria x ananassa Duch.). Revie. Pape., 8, 218-226 (2009).

Karma, B., S. Kumar, A.K. Gupta and M.M. Syamal: Effect of organic, inorganic and biofertilizer on growth, flowering, yield and quality of strawberry (Fragaria x ananassa Duch.) cv. Chandler. Int. J. Curr. Micro. App. Sci., 6, 2932-2939 (2017).

Khalil, H.A.: The potential of biofertilizers to improve vegetative growth, nutritional status, yield and fruit quality of flame seedless grapevines. American-Eurasian J. Agric. Env. Sci., 12, 1122-1127 (2012).

Kirad, K.S., S. Barche and D.B. Singh: Response of integrated nutrient management in strawberry (Fragaria $x$ ananassa D.). Acta. Hort., 842, 653-656 (2009).

Kirimi, J.K., F.M. Itulya and V.N. Mwaja: Effects of nitrogen and spacing on fruit yield of tomato. African J. Horti. Sci., 5, 50-60 (2011).

Latef, A.A.H.A. and H. Chaoxing: Effect of arbuscular mycorrhizal fungi on growth, mineral nutrition, antioxidant enzymes activity and fruit yield of tomato grown under salinity stress. Scien. Hort., 127, 228- 
233 (2011)

Lingua, G., E. Bona, P. Manassero, F. Marsano, V. Todeschini, S. Cantamessa and G. Berta: Arbuscular mycorrhizal fungi and plant growth-promoting pseudomonads increases anthocyanin concentration in strawberry fruits (Fragaria $x$ ananassa var. Selva) in conditions of reduced fertilization. Int. J. Mole. Sci., 14, 1620716225 (2013).

Nazir, N., S.R. Singh, A. Khalil, M. Jabeen and S. Majeed: Yield and growth of strawberry cv. Senga Sengana as influenced by integrated organic nutrient management system. Env. Eco., 24, 640-651 (2006).

Odongo, T., D.K. Isutsa and J.N. Aguyo: Effects of integrated nutrient sources on growth and yield of strawberry grown under tropical high-altitude conditions. African J. Hort. Sci., 1, 53-69 (2008).

Pandit, B.A., H. Aamir, H. Gousia, H. Shazia and M.F. Ahmad: Response of biofertilizers on vegetative growth and yield of strawberry under subtropical conditions of U.P. Progressive Hort., 45, 58-62 (2013).

Panse, V.G. and P.V. Sukhatme: Statistical Methods for Agricultural Workers. Indian Council of Agricultural Research, New Delhi, pp. 361, https:// doi. org/ 10.2134/ agronj 1956. 0002196200480007 0014x (1954).

Patil, N.M.: Biofertilizer effect on growth, protein and carbohydrate content in Stevia rebaudana var. Bertoni. Recent Res. Sci. Tech., 2, 42-44 (2010).

Reddy G.C., R.K. Goyal, S. Puranik, V. Waghmar, K.V. Vikram, K.S. Sruthy: Biofertilizers toward sustainable agricultural development. In: Plant Microbe Symbiosis. (Eds.: A. Varma, S. Tripathi and R. Prasad). Springer, Cham. https://doi.org/ 10.1007/ 978-3-03036248-57 (2020).

Seneviratne, G., M.P.N.K. Henakaarchchi, M.L.M.A.W. Weerasekara and K.A. Nandasena: Soil organic carbon and nitrogen pools as influenced by polyphenols in different particle size fractions under tropical conditions. J. National Sci. Found. Sri Lanka., 37, 67-70. (2009).

Sindhu, S.S., V. Nisha, D. Seema and C. Deepika: Biofertilizer application for growth stimulation of horticultural crops. Haryana J. Hort. Sci., 39, 48-70 (2010).

Singh, D., S. Kumar, R.S. Verma, R. Maurya and A. Shukla. Effect of organic manure and biofertilizers on quality parameters of strawberry (Fragaria $x$ ananassa Duch.) cv. Chandler. J. Pharma. Phyto., 7, 1227-1228 (2018).

Singh, S., N.P. Singh, R. Sharda and A.K. Sangwan: Response of irrigation, fertigation and mulching on plant growth and fruit yield of strawberry. Indian J. Hort., 76, 233-240 (2019).

Sinha, R.K., S. Herat, D. Valani and K. Chauhan: Vermiculture and sustainable agriculture. J. Agric. Env. Sci., 5, 51-55 (2009).

Sonsteby, A., A. Nes and F. Mage: Effects of bark mulch and NPK fertilizer on yield, leaf nutrient status and soil mineral nitrogen during three years of strawberry production. Acta Agricul. Scandin. Sec. B-Soil Plant Sci., 54, 128-134 (2004).

Subraya, B.K., D. Madaiah and M.D. Kumar: Effect of integrated nutrient management on growth and physiological parameters of strawberry (Fragaria x ananassa Duch.) under naturally-ventilated polyhouse. Int. J. Farm Sci., 7, 72-75 (2017).

Tawaraya, K., M. Naito and T. Wagatsuma: Solubilization of insoluble inorganic phosphate by hyphal exudates of arbuscular mycorrhizal fungi. J. Plant Nut., 29, 657-665(2006).

Tonutare, T., U. Moor and L. Szajdak: Strawberry anthocyanin determination by $\mathrm{pH}$ differential spectroscopic method- How to get true results. Acta. Horti., 13, 35-47 (2014).

Tulipani, S., B. Mezzetti and M. Battino: Impact of strawberries on human health: Insight into marginally discussed bioactive compounds for the Mediterranean diet. Pub. Hlth. Nut., 12, 1656-1662 (2009).

Verma, J. and V.K. Rao: Impact of INM on soil properties, plant growth and yield parameters of strawberry cv. Chandler. J. Hill Agri., 4, 6167 (2013).

Wang, S.Y. and K.S. Lewers: Antioxidant capacity and flavonoid content in wild strawberries. J. American Soc. Hor. Sci, 5, 629-637 (2007).

Wani, R.A., S. Sheema, T.H. Malik, S. Geelani, S. Bashir, N.A. Dar and V.M. Prasad: Impact of integrated nutrient management on growth, yield and quality of strawberry (Fragaria $x$ annanassa Duch.) cultivation in India. Ad. Hort. Sci., 27,147-151 (2013).

Zhao, D., K.R. Reddy, V.G. Kakani and V.R. Reddy: Nitrogen deficiency effects on plant growth, leaf photosynthesis and hyperspectral reflectance properties of Sorghum. Europ. J. Agron., 22, 391-403 (2005). 